\title{
Academic Dishonesty among Undergraduate Students in a Korean University
}

\author{
Rodolfo G Ledesma \\ Department of International Trade \\ Konkuk University \\ 1 Hwayang-dong, Gwangjin-gu, Seoul, Korea 143-701 \\ Tel: +82-10-7519-4119Ｅ-mail: rudygledesma@gmail.com
}

Received: August 4, $2011 \quad$ Accepted: September 4, $2011 \quad$ doi:10.5430/rwe.v2n2p25

This work was supported by the faculty research fund of Konkuk University in 2008.

\begin{abstract}
The purpose of this exploratory study is to examine the determinants of alternative forms of academic misconduct among undergraduate students in a Korean university. An economic model of college cheating is estimated using logistic regression. The study differs from other studies in that it frames the issue of academic dishonesty in the context of recent developments to internationalize higher education in Korea, highlighting certain unique aspects of the Korean educational system that are undergoing rapid change and have largely remained unexamined in the literature. The presence of a native English-speaking foreign instructor in class, English-taught classes, and class levels are significant predictors of in-class cheating and such types of academic misconduct as seeking outside help and plagiarism. GPA, class size, cheating tolerance, and study-abroad experience are significant in some types of illicit academic behavior but not in others. Gender and being a foreign student turn out to be weak predictors.
\end{abstract}

Keywords: College Cheating, Logistic Regression, South Korea, Foreign Faculty

\section{Introduction}

An increasing volume of recent studies on academic cheating taking place in schools outside of the U.S. context in such places as Hong Kong (Chapman \& Lupton, 2005), Croatia (Hrabak et al., 2004), Taiwan (Lin \& Wen, 2007), Lebanon (McCabe, Feghali \& Abdallah, 2008), Australia and Iran (Mirshekary \& Lawrence, 2009), India (Taylor-Bianco \& Deeter-Schmelz, 2007), Portugal and Spain (Teixeira \& Rocha, 2008), 21 countries in the continents of Europe, the Americas, Africa and Oceana (Teixeira \& Rocha, 2010), and Romania (Teodorescu \& Andrei, 2009) suggest a bigger, more widespread phenomenon than previously considered. There has also been some research done along the lines of Korean students' perceptions of business ethics (Ahmed, Chung \& Eichenseher, 2003; Chung, Eichenseher \& Taniguchi, 2008) or, as part of a broader group with a 'strong Eastern culture,' their attitudes toward capitalism and unethical business practices (Crittenden, Hanna \& Peterson, 2009). Yet, on the whole, there is a relative dearth of econometric studies on college cheating by Korean university students. This is not to suggest that academic cheating does not happen in Korean universities. For example, Gress and Ilon (2009) cite a 2009 survey reporting that about $27 \%$ of students in a top Korean university had cheated on an exam and about $25 \%$ bought papers online.

The primary purpose of the present study is to fill this gap in the literature - to examine the determinants of alternative forms of academic misconduct among students in a Korean university. Although the study is based on a sample drawn from a single South Korean university, its findings have broad implications for the teaching and classroom management of foreign instructors in Korea and for global education in general.

\section{Background}

An outgrowth of the vigorous internationalization of higher education in South Korea in the past few years has been the urgent need to hire foreign, native speakers of English. The Korean Education Development Institute reported that at the end of 2009 a total of 4,127 full-time foreign professors, mostly from the U.S. and Canada, were working in Korean universities, more than a two-fold jump from the 1,931 reported in 2006. In the Seoul campus of the study institution, the number of foreign professors has surged by more than 3 times from 22 in 2005 to 73 in 2010 . And in one of its fifteen colleges in the same Seoul campus, English-taught courses as a fraction of the total courses offered increased 
from zero in 2003 to $38 \%$ in 2010. The Korean Ministry of Justice has reported that the number of foreign students in the country multiplied from 24,797 in 2005 to 82,096 in 2010 . The number of international students in the study school, a majority of which are from China, increased almost ten-fold from 169 in 2005 to 1,596 in 2009.

Gress and Ilon (2009) raise the question about the preparation of the newly hired foreign professors in the middle of the seeming rush by Korean universities to globalize their curriculum and faculty. The foreign instructor could face the challenge of how to get across to his or her students the importance of academic ethics, which derives from the ideal of respect for ownership of a piece of work (Croxford, 2001). The foreign instructor, one who is likely to come from an individualist environment orientation, may have a completely different definition of what constitutes academic integrity given that his/her domestic students are likely to come from a collectivist setting (Chapman \& Lupton, 2004). A further complicating factor is the fact that the number of foreign students, particularly those from China, who are attending Korean universities is also rising. Now the foreign instructor has to contend not only with the cultural norms and backgrounds of the domestic students but also those of the foreign students as well. Even among students of similar collectivist (Confucian) societal orientation there are differences in perceptions about ethical norms in business (Chung et al. 2008).

The current study differs from other studies in that it frames the issue of academic dishonesty in the context of recent developments in the race to internationalize higher education in Korea. Accordingly, in examining the determinants of unethical academic behavior among college students, it highlights certain unique aspects of the Korean educational system that are undergoing rapid change and have largely remained unexamined in previous literature, namely: (1) the use of English-speaking foreign professors, (2) the introduction of English-taught classes, (3) the small but fast-growing body of international students, and (4) compared to other student groups from other countries, relatively more Koreans study abroad.

\section{Methodology}

This study follows the methodology in the economics literature formulated by Bunn, Caudill and Gropper (1992) and extended by Mixon (1996). Under this framework, which is based on the early work of Becker (1968) and others (Stigler, 1970; Ehrlich, 1973; Reynolds, 1980) on criminal behavior, academic cheating may be likened in a number of ways to theft or tax evasion where the perpetrator is assumed to make a rational decision based on the costs and benefits involved in the criminal act. It is straightforward to imagine that stealing something that you do not own bestows you with some benefits from the possession of the idea or physical property. In the classroom setting, the cheater could reap the benefits of a higher grade like a scholarship, better internship opportunities or a good job. But the act is not costless. It might take time and effort to pull it off, avoid getting caught and thrown in jail. And if you get caught, the penalties could be severe. If caught and punished, the student could lose all those benefits and perhaps more. The question going through the mind of the student is: "Is it worth it?" A student is less likely to cheat if the chance of being caught is high, all else equal. Higher penalties from apprehension also raise the expected costs associated with the dishonest act, deterring the misbehavior. Thus, other things the same, if the expected benefits or gains from the cheating act outweigh the expected costs of committing the act, it is reasonable to expect that a rational cheater would commit more of it, and vice versa.

\subsection{Data Collection}

The study institution where the survey was conducted is a private university with a population of about 18,000 students in its Seoul campus. The data were collected using convenience sampling. Survey questionnaires were handed out to individual faculty members who volunteered to conduct the surveys in their classes in the fall 2009 semester. Students were informed that the survey was anonymous and voluntary. Almost everyone present in class the day of the survey took it, ensuring a high response rate. Students who had taken the survey earlier in another class were not allowed to take it again. Although nonresponse bias did not appear to present a problem, the author is aware that the responses may not be representative of the entire population of the university. Since some of the surveys were conducted by Korean professors, a Korean version was translated from the English version (and then back-translated) for clarity of meaning and content validity. Class size information was gathered as well as demographic data on gender, class level, major, GPA, study-abroad experience, country of origin, and whether the class was taught in English and/or taught by a foreign instructor.

There were 273 usable responses. The demographic data of the survey results showed that male students represented $66 \%$ of the sample. The sample had a disproportionate number of upper-class students with seniors accounting for $30 \%$ and juniors $37 \%$. The mean GPA was 3.5 (4.5 scale) with a standard deviation of 0.45 . The foreign students in the survey, mostly exchange students in their second semester of study in the university, numbered 27, of which 18 were from China and the rest from Europe, all in their first time to study abroad. More than half (63\%) of the students in the 
sample indicated a small class size. About $30 \%$ responded that they had studied abroad. Respondents also indicated that the average number of years that they had studied English before starting college was 8.59 (Std. deviation $=3.71$ ) Students in the sample included those majoring in education, biology, construction, chemistry, geography, mathematics, law, business, economics, engineering, international trade, statistics, politics, information technology and literature.

\subsection{Self-Report Measures of Academic Dishonesty}

Table 1 shows the items in the survey and the associated descriptive statistics of the individual responses. Seven of the eight questions in the survey formed a subset of the twelve measures of academic dishonesty developed by McCabe and Trevino (1993). The last item-(8), finding or buying a paper off the Internet and submitting it as own work-was added based in part on the work of Iyer and Eastman (2006). To measure the student's attitude towards cheating, the survey also asked the question: Have you seen a student who was cheating or copying from another but you did not report it? It is labeled TOLERANCE in Table 1 . The response items were scored on a 5 -point scale $(0=$ no, $1=$ once, . , $4=$ more than 3 times).

Bisping, Patron and Roskelley (2008) examined thirty one types of academic misbehavior, from the most commonly known - copying from another student during a test — to perhaps the less frequent type but still familiar-formatting the margins on a report to make it appear longer than it really is. They argue, as this study does on a much smaller scale, that each one of these types of cheating behavior deserves its own 'unique set of determinants.' As such, they estimated 31 equations. In terms of the number of measures of academic dishonesty used in other studies, the list of survey questions examined in this study is not exhaustive but is consistent with the exploratory nature of the effort. Here the questions do cover three of the four broad classifications of cheating identified by Iyer and Eastman (2006): (i) in-class cheating; (ii) outside help, and; (iii) plagiarism. Missing from the list is a survey question that Iyer and Eastman (2006) consider as falling under the category of "electronic cheating" with a cell phone. Table 1 shows an acceptable scale reliability coefficient (Cronbach's $\alpha$ ) of 0.74 for the survey responses.

$<$ Table 1 about here $>$

Between $21 \%$ and $69 \%$ of undergraduate students in the study institution cheat in one form or another at least once. The preponderance of academic misconduct falls under the subgroup category of 'outside help,' an early indication of a strong tendency for cooperative-type behavior found in countries with an Eastern culture. On average about two thirds of the respondents self-report having committed this type of cheating at least once. About a third of the students in the sample here exhibit some level of tolerance towards cheating. It is likely there could be some underreporting. The distribution of the responses under the 'cheating' category is highly skewed for all three types, with about a third or less of the students reporting having committed this sort of illicit classroom behavior once or greater. In a comparative study between American and Hong Kong business students, Chapman and Lupton (2004) found that both groups tended to underreport the extent of their involvement in in-class cheating.

\subsection{The Economic Model}

Following the economic models expounded by Bunn et al. (1992) and Mixon (1996), which were in turn based on the early work of Becker (1968) and Erlich (1973), and Kerkvliet's adaptation (1994), the propensity for academic dishonesty is modeled as a (reduced-form) function of the variables listed in the formulation below serving as proxies for the expected benefits and costs associated with cheating along with a host of individual difference factors.

$$
\begin{aligned}
\text { DISHONESTY }=\alpha+ & \beta_{1} G P A+\beta_{2} S M A L L \_C L A S S+\beta_{3} F R N \_P R O F+\beta_{4} E N G L I S H \_C L A S S+\beta_{5} M A L E \\
& +\beta_{6} \text { JUNIOR }+\beta_{7} S E N I O R+\beta_{8} S T U D Y \_A B R O A D+\beta_{9} F R N \_S T U D E N T \\
& +\beta_{10} \text { TOLERANCE }+\varepsilon
\end{aligned}
$$

The rational individual weighs the benefits and costs prior to deciding on a utility-maximizing course of action - whether to cheat or not. The student is likely to cheat if the expected utility from cheating exceeds his/her expected utility from abstaining from the act. In this model, the dependent variable is a latent variable designed to measure the likelihood of the student cheating. In expression (1) above, the dichotomous dependent variable DISHONESTY represents the student's response or self-report answer to each of the eight cheating questions. Since there are eight questions each representing a form of academic misbehavior, eight models or equations are estimated. Following Hrabak et al. (2004) the five-point scale responses from each question were dichotomized for estimation purposes, i.e., collapsed into two (the " 0 " and " 1 " scores were coded simply as $0=$ infrequent, while the " 2 ," " 3 " and "more than 3 " scores were lumped as 1 = frequent), and logistic regression was used.

\subsection{Hypotheses}


The self-reported predictor variable GPA, a proxy for the benefit of expected higher returns from schooling, is widely used in the cheating literature as a measure of the academic achievement of the individual student (Bunn et al., 1993; Mixon, 1996; McCabe \& Trevino, 1997; Iyer \& Eastman, 2006; Bisping et al., 2008; Eastman et al., 2008; Teixeira \& Rocha 2008, 2010; Teodorescu \& Andrei, 2009). The reasoning is that a student with a higher GPA has more at stake than another with a lower GPA and so is less likely to cheat, other things the same. On the other hand a student with a lower academic achievement has less to lose and more to gain from cheating. Thus, that student is more likely to indulge in cheating than another who is more academically accomplished. As with other studies, it was hypothesized that GPA is inversely related to academic dishonesty.

It is also hypothesized that the size of the class can be used as a proxy for the likelihood of being detected cheating in class. Other things the same, the smaller the size of the class, the greater is the probability of detection and being punished and so the cost of cheating is higher. Hence, one would expect that the likelihood of cheating is lower. Kerkvliet and Sigmund (1999) used square footage constructed from class rosters and building blueprints in their U.S study of cheating behavior among economics students. Here students were asked if they thought their class was big or small. The dummy variable SMALL_CLASS took on a value of 1 if the student indicated a small class and 0 otherwise. A negative sign was expected.

The next class of dichotomous predictor variables were FRN_PROF, which took on a value of 1 if the instructor was foreign, 0 otherwise, and ENGLISH_CLASS, which was coded 1 if the class was taught in English, 0 otherwise. While a number of Korean universities have been hiring foreign instructors for some time now, for others, including the study institution where the effort has only recently picked up steam, it is a more recent phenomenon. At a transition stage like this one, students may still be learning to adjust to the teaching styles of their foreign instructors (Sidrys \& Jakstaite, 1994; Gress \& Ilon, 2009). Foreign instructors from Western schools are more likely to employ learner-centered pedagogical techniques that are different from the teacher-centered approaches of their Korean counterparts without necessarily implying that the former are any better. Examples include group projects, team reports of case studies, and other, more participatory-type of engagements like classroom discussions and team presentations that form the basis for evaluating learning in addition to or in lieu of straightforward individual in-class exams (Smithee, Greenblatt \& Eland, 2009). Long accustomed to classes conducted in Korean, students may also lack confidence in their ability to communicate in English despite enormous resources and years spent learning the language (Chang, 2009). One would expect the presence of a foreign instructor to have a dampening effect on academic misbehavior, hence, a negative sign was expected for FRN_PROF. On the other hand, if a class were taught in English, students might be more inclined to cheat one way or another to try to overcome hardships with a second language or compensate for a deficiency in English, hence, a positive sign was expected for ENGLISH_CLASS. It should be pointed out that not all English-taught classes in the study institution are taught by foreign instructors. Some Korean professors with graduate degrees from Western schools teach some of their classes in English.

McCabe and Trevino (1997), Hrabak et al. (2004) and Iyer and Eastman (2006) found men to have a higher level of academic dishonesty than women. Kerkvliet (1994) observed that men cheated less than women although in a later study (Kerkvliet \& Sigmund, 1999) concluded that gender did not have an influence on academic misconduct. Tibbetts (1999) also found men to have scored significantly higher than women on their intentions to cheat. Eastman et al. (2008) and Teodorescu and Andrei (2009) did not find gender a significant predictor. Teixeira and Rocha (2008) did not find gender playing a role in their study predicting cheating behavior of students in Spain and Portugal. In this study, MALE is a binary predictor variable that takes on a value of 1 if a student is a male, 0 otherwise. However, no particular expectation with respect to its sign was assigned $a$ priori to this variable.

The literature is also mixed on the influence of age or class level on academic dishonesty. Using age as a predictor, McCabe and Trevino (1997) found older students to have a lower propensity to cheat than younger students. On the other hand, upper-level medical students cheated more than pre-clinical students (Hrabak et al., 2004). Bisping et al. (2008) showed contrasting results for age and class level as predictors-older students were less prone to be academically dishonest but upperclassmen were more likely to cheat than lowerclassmen. Eastman et al. (2008) concluded that the higher the class level of insurance students, the more likely they were to cheat compared to other business majors. 'Year of study' was not a significant predictor of college cheating in the case of Romanian students (Teodorescu \& Andrei, 2009). While age was not found to be a significant factor in influencing academic cheating, Teixeira and Rocha (2008) observed that year of schooling was. In their larger study (Teixeira \& Rocha, 2010), they also found that older students close to getting their degree were more inclined to cheat and the age variable itself was partly a negative, significant predictor. Lacking separate data on the age of the respondents, this study used only class level - represented by the binary variables JUNIOR and SENIOR - as proxies. With each of these variables coded as 1 if a student was a senior or junior as the case may be and 0 otherwise, it follows that freshmen and sophomores as a group 
served as the reference variable. The further along a student is in college, the more likely is the student to engage in academic misconduct. The expectation is that upperclassmen in this university begin to see the light at the end of their academic career. They would be preoccupied with internships and job interviews, affording them less time for actual study, and, sometimes because this could also cause a number of them to begin to miss more classes, resorting to shortcuts associated with academic infractions. Hence, a positive sign was expected.

Unlike other econometric studies that ignore the presence of foreign students within their school or university samples, this study takes a different approach by accounting for those students. The increasing globalization of many universities and the heightened awareness shown by faculty to adapt their teaching to this new environment (Chapman \& Lupton, 2004; Gress \& Ilon, 2009; Smithee, 2009) appear to demand better recognition of these developments. Here, international students, mentioned earlier as a group who would likely not have English as a first language, may be expected to also be adjusting to what for most of them would be a new learning environment. This uncertainty could hold them back from engaging in illicit academic behavior although at the same time, like the local students in the university, they would also be expected to try hard to overcome the English language handicap. The dummy variable FRN_STUDENT is coded 1 if the respondent is a foreign student, 0 otherwise. With respect to its influence on cheating of any form, no particular expectation on the sign of the coefficient was assigned a priori.

The influence of a study-abroad experience on college cheating upon the student's return home has not been previously examined. With the U.S. and other English-speaking countries as the favorite destinations of Korean students going overseas, it seems natural to ask how a study-abroad stint would affect their ethical education. As in other Western schools, foreign students in the U.S. are expected to adhere to the institution's standards of academic integrity, express their individual opinions without help or influence from friends or classmates, and adhere to the rules of good writing and referencing as practiced in the Western scholarship tradition (Duff, Rogers \& Harris, 2006; Smithee et al., 2009). A number of studies have reported the difficulties of Asian students adjusting academically to issues like plagiarism and English as a second language (ESL) while studying in Western schools (Hayes \& Introna, 2005; Maxwell, Curtis \& Vardanega, 2008) and the intervention policies undertaken to deal with them (Duff et al., 2006; Gu \& Brooks, 2008). In U.S. classrooms that conform to the Socratic method of interactive learning, the ESL issue can become quite acute for international students because they are expected to engage in learner-centered activities like class discussions and are partly and sometimes heavily evaluated on such participations (Smithee et al, 2009). But it has also been noted that Asian students are responsive and able to adapt to the demands of their new learning environments while studying abroad (Maxwell et al., 2009; Volet \& Renshaw, 1996; Wong, 2004). Thus, one could argue that given the likely gain in the student's English proficiency as a result of the college overseas experiences and, in addition, his/her having been exposed to the writing conventions in the Western context and the importance of authorial identity could translate to less cheating once the student is back home, all else equal. The dummy variable STUDY_ABROAD was coded 1 if the student indicated having studied abroad and 0 otherwise. The expectation as to the sign of its coefficient was negative.

This study singles out for discussion, apart from the other independent variables, the student's attitude towards cheating. It recognizes the conditioning effect on the student's attitude from observing others cheat. Observing others do it and not doing anything about it may constitute tacit approval. Hrabak et al. (2004) found 'approval of cheating' to be the most important predictor of academic dishonesty among Croatian medical students. The separate treatment is also done partly to highlight what some studies have concluded: that students' observation of the unethical academic behavior of their peers exerts the most influence on their own propensity to cheat (McCabe \& Trevino, 1993, 1997; McCabe et al., 2008), presumably affecting their attitude. The reasoning is that if other students cheat and succeed at it, it could influence the observer to do the same, not wanting to lose out on the opportunity. Teodorescu and Andrei (2009) also found peer dishonesty as the most influential explanatory variable of intent to cheat among Romanian students. In their study, Grimes and Rezek (2005) asked a yes/no question to measure the 'acceptability' of the illicit act and found it a significant predictor in explaining classroom academic misconduct. In their view, those believing that it is socially acceptable to cheat may not suffer as much of a psychic cost from the indulgence as those who believe otherwise. Here, the count variable TOLERANCE is a measure that combines the frequency of the students' observation of their peers' infraction and whether they had reported it. It is hypothesized that the higher the frequency of observing a fellow student cheat and not reporting it, the greater the tolerance for cheating, i.e., the lower the psychic cost if the latter serves as such a proxy, hence, the more a student is likely to misbehave academically. A positive sign was expected.

\section{Regression Results and Discussion}

Table 2 shows the significant marginal effects on the dependent variable of a unit change in the independent variable calculated from the significant regression results of the different logistic models. The $p$-values shown in the table indicate that the fitted logistic regression models are statistically significant overall at an acceptably high level. H-L $\chi^{2}$ 
(8) is the Hosmer-Lemeshow specification test calculated from a table of observed and fitted frequencies using a subgroup of 10. Except for models $Q_{2}$ and $Q_{3}$ the results from Table 2 suggest that the assumed distributions for the logit models fit the data well. For these two the H-L test statistic is significant $(p<0.05)$, suggesting that the null hypothesis of a good model fit to the data is rejected at the $5 \%$ level or better.

$<$ Table 2 about here $>$

Alternatively, using 0.5 as the cut-off, i.e., as the threshold or chance level, the last row in Table 2 shows the overall percentage of correct classification when comparing the proportion of students who self-reported cheating that the model correctly specifies as such with the fraction of students who self-reported as not cheating and that the model correctly classifies as not cheating. These correct predictions range from a low of $67 \%$ to a high of $94 \%$. The average of $77 \%$ for the set of all equations is an improvement over the chance level and comparable to the results obtained by Grimes and Rezek (2005).

GPA comes out mostly with the expected minus sign but significant in only two cheating logit equations $-Q_{1}$ and $Q_{2}$. An increase in GPA, a proxy for the benefit of expected higher returns from schooling, say, from 3.5 to 4.5 lowers the likelihood of cheating by $14.1 \%$ and $17 \%$, respectively, other things the same. If the significance of the self-reported grade point average as a predictor is not as well represented in most of the equations as one might have hoped for, a possible mitigating factor may be that students in the study institution are not as worried as much of passing a course as they are of not getting a high grade.

Unlike in Kerkvliet and Sigmund (1999) but consistent with the findings of Nowell and Laufer (1997), there is solid evidence in this study that a small class is a deterrent to in-class cheating but, perhaps as expected, less so or not at all when it comes to illicit acts that involve seeking outside help or plagiarism. In all three cheating logit equations the coefficients for the predictor SMALL_CLASS have the expected negative sign and show significant values. Using the 'prchange' command in STATA, the effect on the predicted probability of cheating is calculated from these significant results assuming a discrete unit change in SMALL_CLASS from 0 to 1 with other variables held constant at their mean. This leads to the conclusion that a change in the student's perception of a class from being large to small, and so enhances the likelihood of being caught, reduces the probability of cheating by about $18 \%$ on average for all three equations.

While perhaps unintended by university administrators, a consequence of greater foreign faculty hiring in the study institution seems to be a lowering of undergraduate cheating. Other than for model $Q_{3}$ the estimated coefficients for $F R N \_P R O F$ all turn out with the correct expected negative sign and are statistically significant at the $5 \%$ or better. Compared to one that is not, a class taught by a foreign professor, the equivalent of a unit change in FRN_PROF from 0 to 1 , is seen to reduce academic misbehavior by $25 \%$ on average, from a low of $15 \%$ in $Q_{1}$ to a high of $46 \%$ in $Q_{5}$, holding all other variables constant at their mean. Part of the reason it might be noted here is the fact that it is not uncommon for a number of foreign instructors to employ case studies and/or team presentations in their classes, teaching and evaluation techniques that are less susceptible to cheating.

At the same time it appears that students exhibit a greater propensity for academic misbehavior when the class is taught in English. The dummy variable ENGLISH_CLASS shows up with the correct positive sign and is significant in seven logit equations at the standard significance levels. It is estimated from these seven significant results that when a class is taught in English as opposed to being taught in Korean, the probability that a student would cheat increases by $21 \%$ on average. In some English-taught classes, whether taught by foreign instructors or Korean professors, students are allowed to use print or electronic dictionaries during exams.

There is little evidence from Table 2 that a male undergraduate student cheats more than his female counterpart in the study institution, a finding that is in agreement with the more recent studies of Eastman et al. (2008) and Teixeira and Rocha (2008). The dummy variable $M A L E$ figures significantly in only one logit equation, $Q_{3}$. In this single instance, the chance of a student resorting to this type of dishonest academic behavior is about $4 \%$ more for a male student than it is for a female student after other things are held constant at their mean. In terms of the odds ratio, the odds of a male student copying from a classmate without consent is 5.8 times greater than the odds are for a female student.

On the other hand junior and senior students are significantly more inclined to indulge in academic dishonesty compared to freshmen and sophomores. $Q_{8}$, the response item that captures reliance on the Internet for essay submissions, presumably in English, figures prominently where the effect of seniority is most pronounced. It is perhaps this equation that best captures the pressures felt by upperclassmen as they near the end of their academic career. The coefficients of JUNIOR and SENIOR are significant in six of the eight estimated equations and with the expected positive sign. Both groups of upperclassmen appear equally likely to engage in academic misconduct (for each variable about $19 \%$ more 
likely than freshmen and sophomores on average) even if the comparable odds ratio from a given equation suggests some difference in magnitude. On the low end of the range, for example, the variables generate odds ratios in the range of $2-2.5$ times greater compared to freshmen and sophomores. But the high odds ratio of 7.1 times for SENIOR calculated from model $Q_{8}$ is somewhat higher than JUNIOR's high of 5.5 times yielded by the same equation. An $F$ test of no difference in the coefficients of JUNIOR and SENIOR is not rejected $(p>0.05)$ in all five cases where the pairs of coefficients are significant in a given equation. The anecdotal evidence commonly heard from the local faculty is that the highly competitive nature of the job market in Korea brought on by a high rate of unemployment among recent college graduates may be causing upper-level students to miss a number of classes as they try to secure in earnest job interviews and internships.

The dummy variable STUDY_ABROAD shows some promise in that it is significant in three of the eight equations-one outside help equation, $Q_{4}$, and both plagiarism logit models, $Q_{7}$ and $Q_{8}$ - and has the correct expected minus sign. All three significant results together yield a negative predicted probability of $20 \%$ on average, other things constant. That is, a student who has gone abroad to study is twenty percent less likely to engage in an illicit academic behavior compared to one who has not.

Table 2 also shows that there is weak evidence, if at all, that dishonest academic behavior is related to being a foreign student. Only once, in logit equation $Q_{3}$, does the coefficient of FRN_STUDENT turn up with the correct expected sign and significance at an acceptable level. If the results from Table 2 are accurate, the predicted probability of a foreign student cheating is $24 \%$ higher on average than if a student were local, other things held constant at the mean. Alternatively, the odds of a foreign student copying from another without consent is 16 times greater than the odds for a Korean student.

Although not shown, the expected positive sign for TOLERANCE turns up in seven of the eight equations, while four of them are seen in Table 2 as significant at the 5 percent level or less. From what can be estimated from the significant results, when a student goes from being intolerant to being tolerant of the academic misconduct he observes, he is more likely to engage himself in academic misconduct of some type 22 percent of the time on average. While this evidence of the social acceptability of cheating is perhaps not overwhelming, it is not very encouraging either for the teacher regardless of nationality primarily because it is hard to ignore.

\section{Conclusions}

Class size, as perceived by students in the study institution, matters in that, controlling for other factors, it lowers the probability of classroom cheating but less so when it comes to illicit academic acts that involve seeking outside help. It is not a factor at all in situations of plagiarism. Except in two classroom-cheating situations, GPA does not factor much in explaining academic dishonesty among undergraduate students in the study institution. There is a significant negative relationship between a foreign instructor-led class and academic misconduct of almost any type. Conversely, a class taught in English appears to create an environment that leads to more academic infractions such as cheating, plagiarism and, for the most part, seeking outside help, all else equal. Gender is not an important determinant. Junior and senior students are more likely than freshmen and sophomores to engage in illicit academic behavior. Students who have gone abroad seem to show less of a tendency to engage in academic misconduct, especially when it comes to plagiarism, compared to those without a similar study-abroad experience. Being a foreign student also does not come out as a strong predictor of unethical academic behavior. The student's tolerance for cheating appears to be a significant predictor of academic misbehavior in some forms but not in others.

If more than any other type of illicit academic behavior classroom cheating is a major concern for the institution, an implication of the study for classroom management is to try to keep class sizes manageable if it can be done. If class size is beyond an instructor's control, then the next recourse is to pursue greater vigilance in the classroom with cheating-deterrent strategies when administering tests in upper-level classes. It is probably wise to avoid out-of-class individual essay assignments that could invite unauthorized collaborations or cutting-and-pasting from the Internet. But if most of the infractions are of the 'outside help' category or involve plagiarism, some other kind of intervention may be called for like a required course on ethics that includes academic integrity. There is some evidence that sustained intervention yields meaningful results (Duff et al., 2006) and may be especially relevant in the case here given that cheating tolerance is a significant predictor across a number of types of academic misconduct in the study institution. Local and foreign instructors might also push for the adoption of a departmental or university-wide honor code system (McCabe \& Trevino, 1993). This study appears to cast a positive light on study abroad and its effect on college cheating, suggesting continued efforts to encourage students to go for overseas learning experiences. 


\section{Acknowledgment}

This work was supported by the faculty research fund of Konkuk University in 2008. The author wishes to thank his colleagues in the Department of International Trade, Professor Jin Ho Bae of the Economics Department, and Professor Philip Inyeob Ji of Monash University for help with the surveys.

\section{References}

Bisping, T.O., Patron, H., \& Roskelley, K. (2008). Modeling academic dishonesty: The role of student perceptions and misconduct type. Journal of Economic Education, 39, 4-21. http://dx.doi.org/10.3200/JECE.39.1.4-21

Bunn, D., Caudill, S. \& Gropper, D. (1992). Crime in the classroom: An economic analysis of undergraduate student cheating behavior. Journal of Economic Education, 23, 197 - 207. http://dx.doi.org/10.2307/1183222

Burrus, R., McGoldrink, K., \& Schuhmann, P. (2007). Self-reports of student cheating: Does a definition of cheating matter? Journal of Economic Education, 38, 3-16. http://dx.doi.org/10.3200/JECE.38.1.3-17

Chang, S. J. (2009). A cultural and philosophical perspective on Korea's education reform: A critical way to maintain Korea's economic momentum. Academic Paper Series on Korea, Vol. 3, \#2, Korea Economic Institute.

Chapman, K. \& Lupton, R. (2004). Academic dishonesty in a global educational market: a comparison of Hong Kong and American university business students. The International Journal of Educational Management, 18, 425-435.

Chung, K.Y., Eichenseher, J. W., \& Taniguchi, T. (2008). Ethical perceptions of business students: differences between East Asia and the USA and among "Confucian" cultures. Journal of Business Ethics, 79, 121 - 132. http://dx.doi.org/10.1007/s10551-007-9391-7

Crittenden, V., Hanna, R. \& Peterson, R. (2009). The cheating culture. Business Horizons, 52, 337-346. http://dx.doi.org/10.1016/j.bushor.2009.02.004

Croxford, L. (2001). Global university education: Some cultural considerations. Higher Education in Europe, 26 (1), 53 $-60$.

Duff, A., Rogers, D., \& Harries, M. (2006). International engineering students-avoiding plagiarism through understanding the Western academic context of scholarship. European Journal of Engineering Education, 31 (6), $673-681$.

Eastman, J., Iyer, R., \& Reisenwitz, T. (2008). The Impact of unethical reasoning on different types of academic dishonesty: An exploratory study. Journal of College Teaching and Learning, 5 (7), 7-16.

Eastman, K., Eastman, J. \& Iyer, R. (2008). Academic dishonesty: An exploratory study examining whether insurance students are different from other college students. Risk Management and Insurance Review, 11 ( ), 209-226. http://dx.doi.org/10.1111/j.1540-6296.2008.00138.x

Ehrlich, I. (1973). Participation in illegitimate activities: A theoretical and empirical investigation. Journal of Political Economy, 81, 521 - 565. http://dx.doi.org/10.1086/260058

Gress, D. \& Ilon, L. (2009). Successful integration of foreign faculty into Korean universities: A proposed framework. KEDI Journal of Educational Policy, 6-2, 183-204.

Grimes, P. W. \& Rezek, J. P. (2005). The determinants of cheating by high school economics students: A comparative study of academic dishonesty in the transitional economies. International Review of Economics Education, 4(2), 23-45.

Gu, Q. \& Brooks, J. (2008). Beyond the accusation of plagiarism. System, 36, 337-352. http://dx.doi.org/10.1016/j.system.2008.01.004

Hayes, N. \& Introna, L. (2005). Cultural values, plagiarism, and fairness: When plagiarism gets in the way of learning. Ethics \& Behavior, 15, $213-231$.

Hrabak, M., Vujaklija, A., Vodopivec, I., Darko, H., Marusic, M. \& Marusic, A. Academic misconduct among medical students in a post-communist country. Medical Education. 38, 276-285.

Iyer, R. \& Eastman, J. (2008). The impact of unethical reasoning on academic dishonesty: Exploring the moderating effect of social desirability, Marketing Education Review, 18, 1 - 13.

Iyer, R., \& Eastman, J. (2006). Academic dishonesty: Are business students different from other college students? Journal of Education for Business, 101-110. http://dx.doi.org/10.3200/JOEB.82.2.101-110 
Kerkvliet, J. \& Sigmund, C. (1999). Can we control cheating in the classroom? Journal of Economic Education, 30, 331-341. http://dx.doi.org/10.2307/1182947

Kerkvliet, J. (1994). Cheating by economics students: A comparison of survey results. Journal of Economic Education, 25(2), 121-33. http://dx.doi.org/10.2307/1183278

Kidwell, L., Wozniak, K., \& Laurel, J. (2003). Student reports and faculty perceptions of academic dishonesty. Teaching Business Ethics, 7, 205-214.

Lin C. H. S., \& Wen, L. Y. M. (2007). Academic dishonesty in higher education — a nationwide study in Taiwan. Higher Education, 54, 85 - 97. http://dx.doi.org/10.1007/s10734-006-9047-z

Magnus, J., Polerovich, V., Danilov, D., \& Savateev, A. (2002). Tolerance of cheating: An analysis across countries. Journal of Economic Education, 33, 125-153. http://dx.doi.org/10.1080/00220480209596462

Maxwell, A., Curtis, G. \& Vardanega, L. (2008). Does culture influence understanding and perceived seriousness of plagiarism? International Journal of Educational Integrity, 4, 25 - 40.

McCabe D. \& Trevino, L. (1993). Academic dishonesty: Honor codes and other contextual influences. Journal of Higher Education, 64, 520-538. http://dx.doi.org/10.2307/2959991

McCabe D. \& Trevino, L. (1997). Individual and contextual influences on academic dishonesty. Research in Higher Education, 38, 379-396.

McCabe, D., Feghali, T. \& Abdallah, H. (2008). Academic dishonesty in the Middle East: Individual and contextual factors. Research in Higher Education, 49, 451 - 467. http://dx.doi.org/10.1007/s11162-008-9092-9

Meade, J. (1992). Cheating: Is academic dishonesty par for the course? Prism, 1. 30 - 32.

Mirshekary, S. \& Lawrence, A. (2009). Academic and business ethical misconduct and cultural values: A cross national comparison. Journal of Academic Ethics, 7, 141 - 157. http://dx.doi.org/10.1007/s10805-009-9093-0

Nowell, C. \& Laufer, D. (1997). Undergraduate cheating in the fields of business and economics. The Journal of Economic Education, 28, 3 - 12. http://dx.doi.org/10.2307/1183170

O'Clock, P. \& Okleshen, M. (1993) A comparison of ethical perceptions of business and engineering majors. Journal of Business Ethics, 12, 677-687.

Park, C. (2003). In other (people's) words: Plagiarism by university students-literature and lessons. Assessment \& Evaluation in Higher Education, 28(5), 471-488. http://dx.doi.org/10.1080/02602930301677

Phau, I. \& Kea, G. (2007). Attitudes of university students toward business ethics: A cross-national investigation of Australia, Singapore, and Hong Kong. Journal of Business Ethics, 72, 61-75. http://dx.doi.org/10.1007/s10551-006-9156-8

Reynolds, M. O. (1980). The economics of criminal activity. In The Economics of Crime, ed. Ralph Adreano and John Siegfried, pp. 27-70. Cambridge: Schenkman Publishing.

Sidrys, R. \& Jakstaite, I. (1994). A survey of students' attitudes towards native and foreign instructors at Lithuanian universities. Lithuanian Quarterly Journal of Arts and Sciences. [Online] Available: http://www.lituanus.org/1994_4/94_4_01.htm (August 3, 2010)

Smithee, M. (2009). Pedagogy Not Policing: Positive Approaches to Academic Integrity at theUniversity. Ed. Tyra Twomey, Holly White, \& Ken Sagendorf (eds). Syracuse: The Graduate School Press of Syracuse University, 2009. [Online] Availiable: http://works.bepress.com/michael_smithee/2 (November 2, 2010)

Smithee, M., Greenblatt, S. \& Eland, E. (2009). U.S. Classroom Culture. NAFSA: Association Of International Educators. Washington, D.C.

Stigler, J. (1970). The optimum enforcement of laws. Journal of Political Economy, 78, 526-536., http://dx.doi.org/10.1086/259646

Taylor-Bianco, A. \& Deeter-Schmelz, D. (2007). An exploration of gender and cultural differences in MBA students' cheating behavior. Journal of Teaching in International Business, 18, 81-99. http://dx.doi.org/10.1300/J066v18n04_05

Teixeira, A. \& Rocha, M. (2008). Academic cheating in Spain and Portugal: an empirical explanation. International Journal of Iberian Studies, 21, 3-22. 
Teixeira, A. \& Rocha, M. (2010). Cheating by economics and business undergraduate students: An exploratory international assessment. Higher Education, 59, 663-701. http://dx.doi.org/10.1007/s10734-009-9274-1

Tibbetts, S. (1999). Differences between women and men regarding decisions to commit test cheating. Research in Higher Education, 40, 323-342.

Volet, S. \& Renshaw, P. (1996) Chinese Students at an Australian University: Adaptability and Continuity. in WATKINS, D. A. and BIGGS, J. B. (eds.) The Chinese Learner: Cultural, Psychological and Contextual Influences. Hong Kong: CERC/ACER

Warring, S. (2010). Facilitating independence amongst Chinese international students completing a Bachelor of Applied Business Studies Degree. Innovation in Education and Teaching International, 47, 379 - 392. http://dx.doi.org/10.1080/14703297.2010.518430

Wong, J. K. (2004). Are the Learning Styles of Asian International Students Culturally or Contextually Based? International Education Journal, 4, 154-166 [Online] Available: http://ehlt.flinders.edu.au/education/iej/articles/v4n4/wong/paper.pdf (December 12, 2010)

Table 1. Descriptive Statistics of Survey Responses $(N=273$; range: $0-4)$

\begin{tabular}{|c|c|c|c|}
\hline Academic Dishonesty Item (scale reliability coefficient $=0.74$ ) & Mean & $\begin{array}{l}\text { Std. } \\
\text { Deviation }\end{array}$ & $\begin{array}{c}\text { \% reporting } \\
\text { one or } \\
\text { more } \\
\text { times }\end{array}$ \\
\hline \multicolumn{4}{|l|}{ Cheating } \\
\hline$Q_{1}$ : copying from another student during a test & 0.77 & 1.27 & 35.2 \\
\hline$Q_{2}$ : using a "cheat sheet" during a test & 0.73 & 1.21 & 35.2 \\
\hline$Q_{3}:$ copying from another student during a test without consent & 0.37 & 0.86 & 20.9 \\
\hline \multicolumn{4}{|l|}{ Outside Help } \\
\hline$Q_{4}$ : working with another student on a paper assigned as individual work & 1.90 & 1.73 & 64.5 \\
\hline $\begin{array}{l}Q_{5} \text { : asking for information about a forthcoming test from another } \\
\text { student who has taken it }\end{array}$ & 1.50 & 1.41 & 68.9 \\
\hline $\begin{array}{l}Q_{6} \text { : sharing information about a test with another student who has yet to take } \\
\text { it }\end{array}$ & 1.48 & 1.48 & 65.2 \\
\hline \multicolumn{4}{|l|}{ Plagiarism } \\
\hline $\begin{array}{l}Q_{7}: \text { copying a few sentences from a published source without mentioning } \\
\text { or referencing the source }\end{array}$ & 1.69 & 1.65 & 62.3 \\
\hline$Q_{8}$ : finding or buying a paper off the Internet and submitting it as own work & 0.85 & 1.32 & 38.8 \\
\hline TOLERANCE: observing another student cheating and not reporting it & 0.75 & 1.37 & 29.3 \\
\hline
\end{tabular}


Table 2. Logistic Regression Results: Significant Marginal Effects $(N=273)$

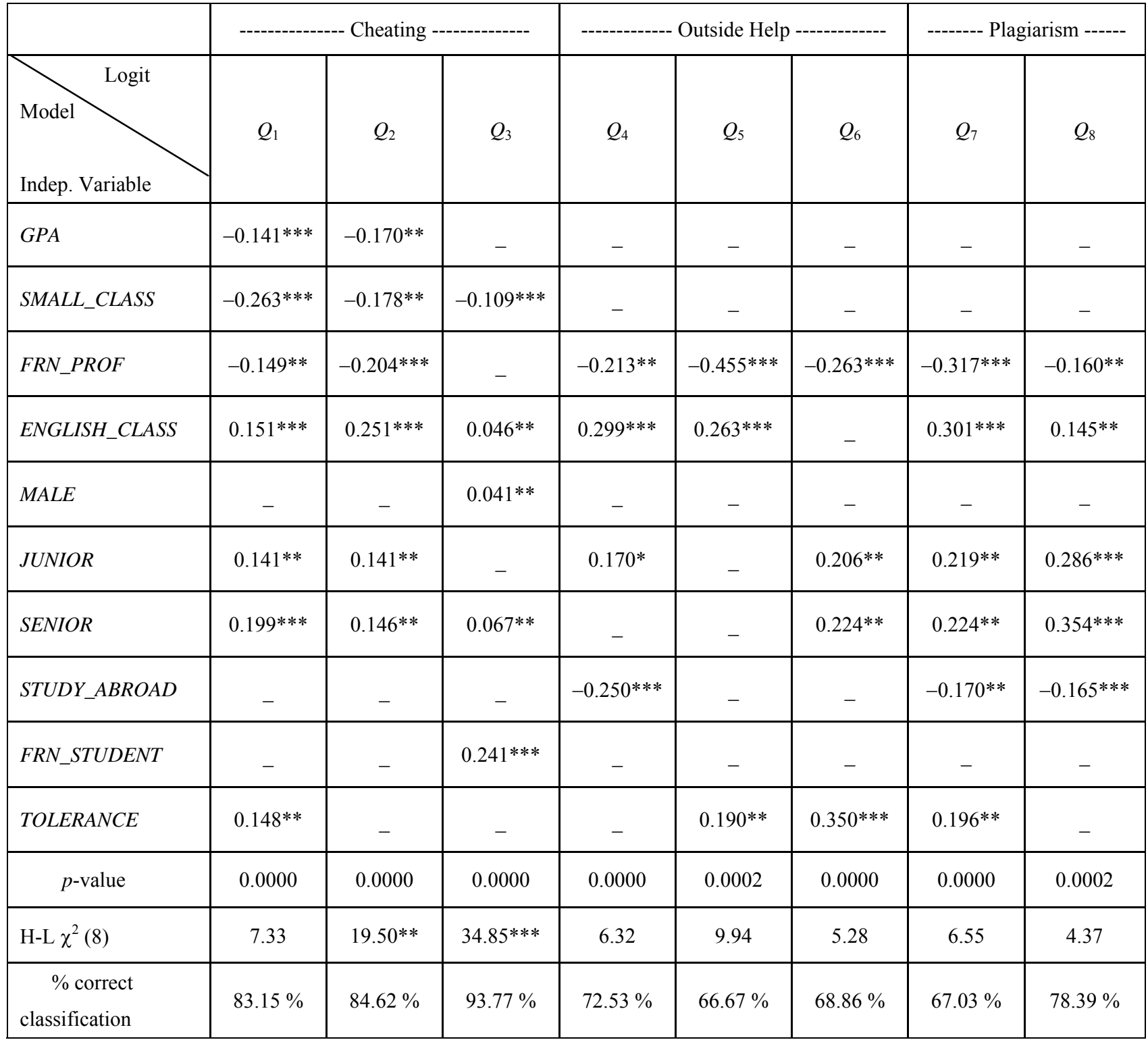

Asterisks, $* * *$ indicates significance at the $1 \%, * *$ at the $5 \%$, and $*$ at the $10 \%$, two-tailed. Marginal effect is calculated as the change in the predicted probability of the dependent variable, say, cheating, from a discrete unit change from 0 to 1 in the relevant regressor holding other variables constant at their mean. Only the significant results are shown but all equations were fitted with a constant. 